\title{
Produtividade de sistemas forrageiros consorciados com amendoim forrageiro ou trevo vermelho
}

\author{
Productivity of pastures-based systems mixed to forage peanut or red clover \\ Ricardo Lima de Azevedo Junior ${ }^{\mathrm{I}}$ Clair Jorge Olivo ${ }^{\text {II }}$ Gilmar Roberto Meinerz ${ }^{\text {III }}$ \\ Carlos Alberto Agnolin ${ }^{\mathrm{III}}$ Michelle Schalemberg Diehl' ${ }^{\mathrm{III}}$ Guidiane Moro ${ }^{\mathrm{III}}$ \\ Carla Lieda Cezimbra Parra ${ }^{\mathrm{III}}$ Mauricio Pase Quatrin ${ }^{\mathrm{IV}}$ Tiago Horst $^{\mathrm{V}}$
}

RESUMO

\begin{abstract}
O objetivo desta pesquisa foi avaliar três sistemas forrageiros (SF) com capim elefante (CE) Pennisetum purpureum Schum., cv. 'MerckeronPinda' + espécies de crescimento espontâneo (ECE) + azevém anual (AZ) Lolium multiflorum Lam., cv. 'Comum', como SF1; CE + ECE + AZ + amendoim forrageiro (AF) Arachis pintoi Krap. e Greg., cv. 'Amarillo', como SF2; e CE + ECE + AZ + trevo vermelho (TV) Trifolium pratense L., cV. 'Estanzoela 116', como SF3. O CE foi estabelecido em linhas afastadas a cada $4 m$. O azevém anual foi estabelecido entre as linhas do CE durante o período hibernal; o TV foi semeado e o AF foi preservado nos respectivos tratamentos. Para avaliação, foram usadas vacas da raça Holandesa que receberam $5,5 \mathrm{~kg} \mathrm{dia}^{-1}$ como complemento alimentar. Foram avaliadas a taxa de acúmulo diário de matéria seca (TA), a massa de forragem desaparecida (MFD), a matéria seca desaparecida com base em $100 \mathrm{~kg}$ de peso vivo (MSD) e a produção de forragem (PF), as composições botânica e estrutural do CE. O delineamento experimental foi o inteiramente casualizado, com três tratamentos (SF) e duas repetições (piquetes) em parcelas subdivididas no tempo (pastejo). Durante o período experimental (341 dias), foram efetuados nove ciclos de pastejo. Os valores médios de TA, MFD, MSD e PF foram de $53,16 \mathrm{~kg} \mathrm{ha}^{-1} ; 36,13 \% ; 2,77 \mathrm{~kg}$ de matéria seca por $100 \mathrm{~kg}$ de peso vivo e 17,80t ha ${ }^{-1}$. Para a variável ECE, houve aumento significativo no SF1. Considerando a carga animal, o SF3 apresentou melhor desempenho.
\end{abstract}

Palavras-chave: Arachis pintoi, bovinos leiteiros, Lolium multiflorum, pastejo rotacionado, Pennisetum purpureum, Trifolium pratense.

\begin{abstract}
The objective of this research was to evaluate of tree pasture-based systems (PS) with elephantgrass (EG) Pennisetum purpureum Schum., cv. 'Merckeron Pinda' + spontaneous growing species (SGS), annual ryegrass (RG) Lolium multiflorum Lam., cv. 'Comum', for PS1; EG + SGS + forage peanut (FP) Arachis pintoi Krap. e Greg., cv. 'Amarillo', for PS2; and EG + $S G S+R G+$ red clover (RC) Trifolium pratense $L$., $C v$. 'Estanzoela 116', for PS3. EG was planted in lines with a distance of $4 \mathrm{~m}$ each one of them. Ryegrass was sowed between rows of EG during the cool-season; red clover was sowed and the forage peanut was preserved on respectively treatments. Holstein cows receiving $5.5 \mathrm{~kg}^{\text {daily }}{ }^{-1}$ complementary concentrate feed were used. The dry matter daily accumulation rate (DMA), disappearance of forage mass (DFM), dry matter disappeared based on $100 \mathrm{~kg}$ of live weight (DMD), total dry matter production (TDM), botanical composition and structural component of EG were evaluated. The experimental design used was completely randomized with tree treatments (SF) and two replicates (paddocks) in incomplete split-plot time (grazing cycles). Nine grazing cycle were performed during the experimental period (341 days). The average values of DMA, DFM, DMD and TDM were $53.16 \mathrm{~kg} \mathrm{ha}^{-1}, 36.13 \%, 2.77 \mathrm{~kg}$ of dry matter per $100 \mathrm{~kg}$ of liveweight and $17.80 \mathrm{t} \mathrm{ha}^{-1}$, respectively. SGS parameter increased significantly over in the PS1. Considering the stocking rate the PS3 showed a better performance.
\end{abstract}

Key words: Arachis pintoi, dairy cattle, Lolium multiflorum, Pennisetum purpureum, rotational grazing, Trifolium pratense.

'Programa de Pós-graduação em Zootecnia, Universidade Federal de Santa Maria, (UFSM), 97105-900, Santa Maria, RS, Brasil. E-mail: ricardo.junior@zootecnista.com.br. Autor para correspondência.

"Departamento de Zootecnia, UFSM, Santa Maria, RS, Brasil.

IIIPrograma de Pós-graduação em Zootecnia, UFSM, Santa Maria, RS, Brasil.

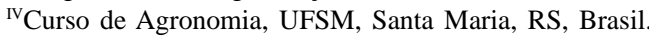

${ }^{v}$ Curso de Zootecnia, UFSM, Santa Maria, RS, Brasil. 


\section{INTRODUÇÃO}

Na atividade leiteira, o capim elefante tem representado, em diferentes regiões do País, uma alternativa importante na alimentação dos animais (DERESZ, 2001). Normalmente, essa forrageira é utilizada de forma singular, sendo utilizadas doses, por vezes, elevadas de adubação nitrogenada (OLIVO et al., 2009). Para as condições subtropicais, em que há o efeito das baixas temperaturas e das geadas, o capim elefante diminui ou paralisa seu crescimento. Assim, para se utilizar a mesma área e complementar a produção de forragem, é necessária a consorciação com espécies de ciclo hibernal, como a aveia, centeio, cevada e o azevém anual.

Agrega-se a isso o uso de técnicas consideradas mais sustentáveis como o consórcio com leguminosas, minimizando a utilização de adubos nitrogenados, além de contribuir para equilibrar a oferta de forragem e a qualidade da dieta no decorrer do ano agrícola. No entanto, o estabelecimento lento das leguminosas e as dificuldades de manejo (CASTILHO, 2001) são condições que podem comprometer a persistência delas na pastagem. Pesquisas sobre consórcios forrageiros sob pastejo com leguminosas são escassas, notadamente envolvendo espécies de ciclos produtivos diferentes.

Particularmente, para a região Sul do Brasil, questiona-se o comportamento do amendoim forrageiro, uma forrageira promissora por seu potencial forrageiro, valor nutritivo e capacidade de fixação biológica de nitrogênio (PERIN et al., 2003), em consorciação com culturas anuais de ciclo hibernal, como o azevém anual e com espécies perenes de porte alto como o capim elefante, com relação a sua perenidade, adaptação, produção e contribuição na dieta dos animais. O trevo vermelho é outra leguminosa utilizada em misturas com gramíneas de inverno, proporcionando um maior período de utilização da pastagem, bom rendimento de forragem, alta qualidade e palatabilidade (PAIM, 1994). No entanto, há escassez de informações sobre o uso dessas leguminosas em consórcio com espécies perenes de ciclo estival, sob condições de pastejo.

Assim, este trabalho teve como objetivo avaliar a produtividade de três sistemas forrageiros constituídos por capim elefante, azevém anual, espécies de crescimento espontâneo e diferentes leguminosas (trevo vermelho ou amendoim forrageiro).

\section{MATERIAL E MÉTODOS}

O trabalho foi conduzido em área experimental pertencente ao Departamento de
Zootecnia da UFSM, situado na região da Depressão Central (Santa Maria, RS), no período de 07/05/09 a 14/ 04/10, totalizando 341 dias. As médias de temperatura e precipitação foram de $19,31^{\circ} \mathrm{C}$ e $2368 \mathrm{~mm}$. Para a temperatura, os valores foram semelhantes às normais. As precipitações excederam a média histórica, exceção feita entre o mês de março e a metade de abril, verificando-se déficit hídrico. O clima da região é o subtropical úmido (Cfa), segundo a classificação de Köppen. Os tratamentos foram constituídos por três sistemas forrageiros, tendo como base o capim elefante, as espécies de crescimento espontâneo e o azevém anual, constituindo-se no tratamento sem a presença de leguminosas; para os demais, agregou-se o amendoim forrageiro ou o trevo vermelho.

A área experimental utilizada foi de 0,78 ha (subdividida em seis piquetes de 0,13 ha cada) com capim elefante (Pennisetum purpureum Schum., cv. 'Merckeron Pinda') já estabelecido, desde 2004, em linhas afastadas a cada 4m. No dia 07 de maio de 2009, foi realizada uma roçada para uniformização da pastagem entre as linhas do capim elefante. No dia 11 de maio de 2009, foi semeado o azevém anual (Lolium multiflorum Lam., cv. 'Comum’), nas entrelinhas de toda área experimental, à razão de $30 \mathrm{~kg} \mathrm{ha}^{-1}$, mediante escarificação do solo. Na área destinada ao trevo vermelho (Trifolium pratense L., cv. 'Estanzoela 116'), fez-se a semeadura à razão de $3 \mathrm{~kg} \mathrm{ha}^{-1} \mathrm{e}$, na área do amendoim forrageiro (Arachis pintoi Krap. e Greg., cv. 'Amarillo'), preservou-se o amendoim forrageiro, já estabelecido desde 2006.

Foram utilizados para a adubação $300 \mathrm{~kg} \mathrm{ha}^{-1}$ de NPK (5-20-20) e $13 \mathrm{~kg} \mathrm{ha}^{-1}$ de $\mathrm{KCl}$, divididos em duas aplicações, sendo a primeira no estabelecimento do azevém anual e a segunda aplicação após o quarto pastejo, a análise de solo apresentou os seguintes valores médios no início do período experimental: Índice

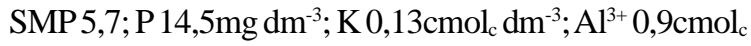
$\mathrm{dm}^{-3} ; \mathrm{Ca}^{2+} 5,5 \mathrm{cmol}_{\mathrm{c}} \mathrm{dm}^{-3} ; \mathrm{Mg}^{2+}$ 2,3 $\mathrm{cmol}_{\mathrm{c}} \mathrm{dm}^{-3} ; \mathrm{MO} 3,0 \%$; saturação de bases $54,0 \%$ e saturação por alumínio 12,2\%. Como adubação de cobertura, utilizaram-se $45 \mathrm{~kg}$ ha $^{-1} \mathrm{ano}^{-1}$ de N, sob forma de ureia, parcelada em três aplicações, após o primeiro, terceiro e quinto pastejos.

O critério de utilização da pastagem durante o período hibernal teve como base o desenvolvimento do azevém anual, sendo que o critério para entrada dos animais nas pastagens se dava quando este se encontrava com cerca de $20 \mathrm{~cm}$ de altura; no período estival, a altura do capim elefante foi entre 80 e $100 \mathrm{~cm}$. Antecedendo a entrada dos animais, estimou-se a massa de forragem mediante a técnica de dupla amostragem (WILM et al., 1944). No capim elefante, os cortes foram 
feitos a 50cm do solo e nas entrelinhas rente ao solo. As amostras foram pesadas e homogeneizadas, sendo retirada uma subamostra para estimativa das composições botânica da pastagem e estrutural do capim elefante, para a obtenção da massa de lâminas foliares e colmo + bainha, que foram posteriormente secas em estufa para determinação da matéria seca.

Para determinar a carga animal instantânea, procurou-se manter uma oferta de forragem de 7 e $4 \mathrm{~kg}$ de matéria seca por $100 \mathrm{~kg}$ de peso vivo para a massa de forragem da entrelinha e para a massa de lâminas foliares do capim elefante, respectivamente. Como animais experimentais, foram utilizadas vacas em lactação da raça Holandesa, com peso vivo médio de

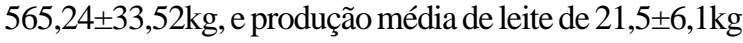
$\mathrm{dia}^{-1}$. Os animais foram submetidos a duas ordenhas, recebendo, em média, $5,5 \mathrm{~kg}$ de concentrado $\mathrm{dia}^{-1}$, e permanecendo nas pastagens das $9 \mathrm{~h}$ às $15 \mathrm{~h} 30 \mathrm{~min}$ e das $18 \mathrm{~h}$ às $6 \mathrm{~h} 30 \mathrm{~min}$.

A taxa de acúmulo das pastagens foi determinada pela diferença entre a massa de forragem do pós e do pré-pastejo, dividindo o resultado pelo número de dias compreendido entre os ciclos de pastejo. A matéria seca desaparecida foi estimada pela diferença entre a massa de forragem de pré e de póspastejo, transformadas em porcentagem.

O delineamento experimental utilizado foi o inteiramente casualizado com três tratamentos (sistemas forrageiros) e duas repetições de área (piquetes) e em parcelas subdivididas no tempo (ciclos de pastejo). Os dados foram submetidos à análise de variância e as médias comparadas pelo teste de Tukey, ao nível de $5 \%$ de probabilidade do erro. As análises foram efetuadas com auxílio do pacote estatístico SAS (1997).

O modelo matemático referente à análise das variáveis estudadas da pastagem foi representado por: $\mathrm{Y}_{\mathrm{ijkl}}=\mathrm{m}+\mathrm{T}_{\mathrm{i}}+\mathrm{R}_{\mathrm{j}}\left(\mathrm{T}_{\mathrm{i}}\right)+\mathrm{C}_{\mathrm{k}}+(\mathrm{TC})_{\mathrm{ik}}+\varepsilon_{\mathrm{ijk}}$, em que: $\mathrm{Y}_{\mathrm{ijk} \mathrm{l}}$ representa as variáveis dependentes; i - índice de tratamentos (sistemas forrageiros); $\mathrm{j}$ - índice de repetições (piquetes); $\mathrm{k}$ - índice de pastejos; $\mathrm{m}$ - média de todas as observações; $T_{i}$ - efeito dos tratamentos; $R_{j}\left(T_{i}\right)$ - efeito de repetição dentro dos tratamentos (erro a); $\mathrm{C}_{k}$ - efeito

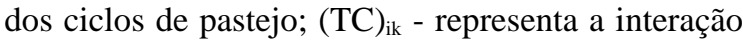
entre os tratamentos e pastejos; $\varepsilon_{\mathrm{ijkl}}$ - erro aleatório residual (erro b).

\section{RESULTADOS E DISCUSSÃO}

Durante o período experimental, foram realizados nove pastejos em ambos os sistemas forrageiros, quatro no período hibernal e cinco no estival. O tempo de descanso variou de 41 a 33 dias nos períodos hibernal e estival, e de ocupação de um a dois dias. Períodos curtos de ocupação, de até três dias, e de descanso, próximo a 30 dias para espécies de ciclos hibernal e estival, estão associados à melhor qualidade da forragem (DERESZ, 2001).

Para a massa de forragem de lâminas foliares do capim elefante ao pré-pastejo (Tabela 1), houve diferença $(P \leq 0,05)$ somente na avaliação efetuada no final de dezembro, com valor superior para a pastagem consorciada com trevo vermelho, havendo similaridade entre as leguminosas. Embora tenha ocorrido apenas em um pastejo, esse resultado aponta para um possível efeito da presença das leguminosas em estudo, que, nesse período, já estão contribuindo com a liberação de nitrogênio para o sistema (PERIN et al., 2003). Para a massa de colmo mais bainha, a diferença ocorrida em setembro tem pouca importância em função da baixa produção verificada. No entanto, a diferença $(\mathrm{P} \leq 0,05)$ observada no pastejo efetuado em abril para o amendoim forrageiro aponta para a mesma tendência, no período em que ocorre a maior contribuição acumulada dessa leguminosa. Também, para a fração de material morto do capim elefante, verificou-se maior massa de forragem para o sistema sob consórcio, no pastejo efetuado em abril, indicando também uma possível contribuição das leguminosas na produção do capim.

Analisando-se o material presente entre as linhas do capim elefante, observa-se que, no período hibernal, não houve diferença entre os sistemas para a massa de forragem do azevém anual. Resultado similar, mas com massa de forragem de pré-pastejo menor, foi observado por OLIVO et al. (2009), ao comparar sistemas semelhantes envolvendo amendoim forrageiro e trevo branco. Dando prosseguimento a este trabalho, STEINWANDTER et al. (2009) verificaram menor disponibilidade de azevém anual no tratamento com amendoim forrageiro, em relação ao consórcio com trevo branco.

Quanto à participação das leguminosas (Tabela 1), observa-se grande variabilidade em função das diferenças genéticas, estruturais, crescimento e dos ciclos distintos de desenvolvimento. As médias de participação foram de 40,82 e 23,10\% para o amendoim forrageiro e o trevo vermelho, respectivamente, considerando-se o espaço ocupado nas entrelinhas. Esses valores são similares à recomendação indicada por THOMAS (1992), de 30\%, proporcionando equilíbrio às perdas de nitrogênio do sistema e contribuindo para manter a fertilidade do solo e a produtividade em longo prazo. Considerando-se a totalidade da área, as médias respectivas são de 25,48 e 14,88\%, estando próxima da recomendação de CADISH et al. (1994), de 13 e 23\% de leguminosas como condição necessária para manter a sustentabilidade do sistema. 
Tabela 1 - Massa de forragem (kg de matéria seca ha ${ }^{-1}$ ) de pré-pastejo de diferentes componentes estruturais e botânicos e lotação (vacas ha ${ }^{-1}$ ) em três sistemas forrageiros. Santa Maria, RS, 2010.

\begin{tabular}{|c|c|c|c|c|c|c|c|c|c|c|c|c|}
\hline \multirow[t]{2}{*}{ Variáveis $^{2}$} & \multirow{2}{*}{$\begin{array}{c}\mathrm{SF}^{1} \\
\mathrm{TE}\end{array}$} & Jul & Ago & Set & Out & Dez & Dez & Jan & Fev & Abr & Média & CV (\%) \\
\hline & & 379 & 0 & 75 & 192 & 934 & $692^{\mathrm{b}}$ & 901 & 982 & 829 & 554 & \\
\hline \multirow[t]{3}{*}{ LFCE } & $\mathrm{AF}$ & 563 & 0 & 104 & 130 & 919 & $810^{\mathrm{ab}}$ & 1058 & 1267 & 1434 & 698 & 12,63 \\
\hline & TV & 443 & 0 & 130 & 158 & 786 & $858^{\mathrm{a}}$ & 957 & 1426 & 1284 & 672 & \\
\hline & $\mathrm{TE}$ & 421 & 0 & $61^{a}$ & 87 & 273 & 432 & 347 & 276 & $317^{\mathrm{b}}$ & 246 & \\
\hline \multirow[t]{3}{*}{ CBCE } & $\mathrm{AF}$ & 443 & 0 & $72^{\mathrm{a}}$ & 42 & 461 & 592 & 404 & 514 & $590^{\mathrm{a}}$ & 358 & 12,34 \\
\hline & $\mathrm{TV}$ & 551 & 0 & $25^{b}$ & 69 & 217 & 721 & 323 & 1181 & $486^{\mathrm{ab}}$ & 385 & \\
\hline & $\mathrm{TE}$ & 114 & 476 & 335 & 415 & 253 & 161 & 232 & 88 & $80^{\mathrm{b}}$ & 239 & \\
\hline \multirow[t]{3}{*}{ MMCE } & $\mathrm{AF}$ & 217 & 368 & 283 & 175 & 221 & 238 & 314 & 142 & $249^{\mathrm{a}}$ & 245 & 13,60 \\
\hline & $\mathrm{TV}$ & 283 & 680 & 453 & 254 & 178 & 170 & 183 & 197 & $233^{\mathrm{a}}$ & 292 & \\
\hline & $\mathrm{TE}$ & 306 & 934 & 1331 & 1714 & - & - & - & - & - & 1071 & \\
\hline \multirow[t]{3}{*}{$\mathrm{AZ}$} & $\mathrm{AF}$ & 545 & 1081 & 1270 & 1449 & - & - & - & - & - & 1086 & 13,84 \\
\hline & TV & 384 & 1098 & 1837 & 1192 & - & - & - & - & - & 1128 & \\
\hline & $\mathrm{TE}$ & - & - & - & - & - & - & - & - & - & - & \\
\hline \multirow[t]{3}{*}{ LEG } & $\mathrm{AF}$ & - & - & - & $324^{\mathrm{b}}$ & 723 & 795 & $1062^{\mathrm{a}}$ & 1111 & 1282 & 883 & 3,17 \\
\hline & $\mathrm{TV}$ & 231 & 344 & 880 & $754^{\mathrm{a}}$ & 616 & 606 & $514^{\mathrm{b}}$ & - & - & 564 & \\
\hline & $\mathrm{TE}$ & - & - & - & - & 525 & 942 & 975 & $1239^{\mathrm{a}}$ & $1790^{\mathrm{a}}$ & 1094 & \\
\hline \multirow[t]{3}{*}{ PAS } & $\mathrm{AF}$ & - & - & - & - & 182 & 403 & 647 & $442^{c}$ & $1542^{\mathrm{a}}$ & 493 & 12,11 \\
\hline & TV & - & - & - & - & 357 & 458 & 778 & $854^{\mathrm{b}}$ & $794^{\mathrm{b}}$ & 798 & \\
\hline & $\mathrm{TE}$ & 102 & 307 & 415 & $776^{\mathrm{a}}$ & 960 & 1060 & $1359^{\mathrm{a}}$ & 921 & 972 & 764 & \\
\hline \multirow[t]{3}{*}{ ECE } & $\mathrm{AF}$ & 56 & 196 & 433 & $574^{\mathrm{ab}}$ & 165 & 487 & $699^{c}$ & 598 & 588 & 422 & 9,36 \\
\hline & TV & 165 & 334 & 365 & $369^{b}$ & 461 & 717 & $1050^{\mathrm{b}}$ & 1000 & 1058 & 613 & \\
\hline & $\mathrm{TE}$ & 316 & 605 & 510 & 478 & 637 & 275 & 403 & 399 & 423 & 460 & \\
\hline \multirow[t]{3}{*}{ MMEL } & $\mathrm{AF}$ & 392 & 743 & 492 & 573 & 576 & 205 & 135 & 271 & 341 & 396 & 16,84 \\
\hline & $\mathrm{TV}$ & 287 & 786 & 615 & 426 & 589 & 274 & 212 & 472 & 173 & 445 & \\
\hline & $\mathrm{TE}$ & 0,44 & 1,49 & 2,11 & 3,17 & 2,13 & 3,89 & 4,61 & 2,89 & 2,79 & $2,61^{b}$ & \\
\hline \multirow[t]{2}{*}{ Lotação } & $\mathrm{AF}$ & 0,63 & 1,63 & 2,09 & 3,02 & 1,84 & 3,69 & 4,69 & 3,14 & 3,22 & $2,66^{\mathrm{b}}$ & 1,55 \\
\hline & TV & 0,59 & 2,07 & 3,46 & 2,90 & 1,92 & 3,96 & 4,51 & 3,26 & 3,12 & $2,86^{\mathrm{a}}$ & \\
\hline
\end{tabular}

‘a b’ médias seguidas por letras distintas, na coluna, diferem entre si pelo teste de Tukey $(\mathrm{P} \leq 0,05)$.

${ }^{1} \mathrm{TE}=$ testemunha, constituído por capim elefante (CE) + azevém anual (AZ) + espécies de crescimento espontâneo (ECE);AF= CE + AZ + $\mathrm{ECE}+$ amendoim forrageiro ; TV= CE + AZ + ECE+ trevo vermelho.

${ }^{2} \mathrm{LFCE}=$ lâmina foliar do $\mathrm{CE}$; $\mathrm{CBCE}=$ colmo + bainha do CE; MMCE= material morto do CE; PAS= Paspalum spp.;LEG= leguminosa; MMEL = material morto da entrelinha.

Peso médio das vacas: $565 \mathrm{~kg}$.

Com relação à produção das leguminosas, destaca-se a massa de forragem ascendente do amendoim forrageiro, com volumes elevados no final do verão e início do outono, podendo prolongar-se nessa estação, estando dependente da ocorrência das primeiras geadas (STEINWANDTER et al., 2009). Para o trevo vermelho, destacam-se as produções no período estival até a avaliação efetuada em janeiro. Esse 
desempenho deve-se, em parte, às precipitações pluviométricas que excederam as normais. Já no pastejo feito em fevereiro, não se obteve massa de forragem para o trevo vermelho, provavelmente, devido ao efeito cumulativo das temperaturas elevadas e à baixa precipitação pluviométrica, confirmando a baixa persistência da cultura diante de condições ambientais desfavoráveis, com verões secos (PAIM, 1994).

Para as espécies de crescimento espontâneo, observa-se que o Paspalum constitui-se no componente de maior participação, com valores mais elevados na pastagem sem leguminosas. As demais espécies de crescimento espontâneo foram constituídas por papuã (Urochloa plantaginea), milhã (Digitaria sanguinalis), guanxuma (Sida santaremnensis), erva-de-bicho (Polygonum persicaria) e a buva (Conyza bonariensis), confirmando-se a mesma tendência com menor presença dessas espécies nas pastagens consorciadas (SARRANTONIO, 1992). Ressalta-se que a composição botânica distinta observada entre as pastagens não implicou diferença na fração de material morto presente na entrelinha.

Já para a lotação (Tabela 1), houve diferença $(\mathrm{P} \leq 0,05)$ para a média dos pastejos, com valor superior para o consórcio constituído por trevo vermelho. Esse resultado deveu-se, notadamente, à contribuição dessa leguminosa no final do inverno. Considerando-se as lotações obtidas nos períodos hibernal, caracterizado pelo tempo de utilização do azevém anual (até outubro), e estival, os valores são semelhantes aos observados na mesma região por STEINWANDTER et al. (2009), de 2,3 a 2,4UA ha-1 e de 3,72 e 4,47UA ha-1, respectivamente, valendo-se de manejo similar e comparando sistemas forrageiros com amendoim forrageiro e trevo branco.

Para a porcentagem de massa de forragem desaparecida (Tabela 2$)$, houve diferença $(\mathrm{P} \leq 0,05)$ apenas no pastejo efetuado em setembro, com menor taxa para o consórcio com amendoim forrageiro. STEINWANDTER et al. (2009) observaram valores mais baixos e irregulares com essa leguminosa em consórcio com azevém anual, na mesma região, devido ao efeito cumulativo do frio e das geadas, que influenciam na qualidade e palatabilidade dessa forragem no final do inverno. Esse resultado é confirmado na massa de forragem desaparecida com base na percentagem do peso vivo, com taxas superiores $(\mathrm{P} \leq 0,05)$ nas pastagens sem leguminosa e com trevo vermelho, havendo inversão na avaliação efetuada em janeiro, com taxa mais elevada na pastagem com amendoim forrageiro em relação ao trevo vermelho. Os baixos valores verificados em fevereiro estão associados à diminuição na qualidade dos materiais presentes na entrelinha, em parte, devido ao déficit hídrico ocorrido. Para as demais taxas, foram observadas diferenças normalmente influenciadas por um dos componentes da pastagem, como na taxa de desaparecimento do azevém anual, que foi menor $(P \leq 0,05)$ na avaliação efetuada em setembro no consórcio com amendoim forrageiro.

Para as leguminosas, as taxas são variáveis em função das características e dos ciclos de desenvolvimento de cada forrageira, destacando-se os valores elevados do trevo vermelho nas avaliações feitas no inverno e as baixas taxas para o amendoim forrageiro em todos os pastejos. Conduzindo trabalho similar, com amendoim forrageiro e trevo branco, STEINWANDTER et al. (2009) verificaram taxas de desaparecimento para o período hibernal de 28,04 e $30,51 \%$ e para o período estival, de 46,53 e $36,76 \%$, para as respectivas leguminosas.

Para as espécies de crescimento espontâneo, não foram observadas diferenças entre as pastagens, tanto nas avaliações quanto nas médias. Observa-se que os valores são mais baixos, se comparados com as taxas de desaparecimento do capim elefante no período estival. No entanto, deve-se destacar que algumas dessas plantas, como o papuã e o milhã apresentam bom desempenho como forrageiras.

Para os valores de matéria seca desaparecida, com base em $100 \mathrm{~kg}$ de peso vivo, foram observadas diferenças em duas avaliações, influenciadas pela presença das leguminosas. Em setembro, a taxa foi maior na pastagem consorciada com trevo vermelho e, em janeiro, o valor foi maior na pastagem consorciada com amendoim forrageiro (Tabela 1), período em que ocorreu o ápice de sua produção e declínio do trevo vermelho que estava em fase de formação de sementes.

Para a taxa de acúmulo diário de matéria seca (Tabela 3), não foram observadas diferenças, tanto na forragem presente na entrelinha quanto na linha, verificando-se os menores valores em agosto e os maiores entre dezembro e fevereiro, com um valor médio de todos os sistemas próximo a $53 \mathrm{~kg} \mathrm{ha}^{-1}$. Taxas entre 50,8 e 119,4kg ha-1 foram observadas por MISSIO et al. (2006), em trabalho conduzido na mesma região com a cultivar Taiwan, manejada singularmente, entre janeiro e março e adubada com $90 \mathrm{~kg} \mathrm{ha}^{-1}$ de nitrogênio na forma de ureia. Valores similares aos do presente trabalho, de $37,38 \mathrm{~kg} \mathrm{ha}^{-1} \mathrm{dia}^{-1}$ para o período hibernal, e $62,6 \mathrm{~kg} \mathrm{ha}^{-1}$ dia $^{-1}$ para o período estival, foram observados por STEINWANDTER et al. (2009), em pastagens consorciadas com distintas leguminosas.

Para a taxa de acúmulo do azevém anual, o valor médio das pastagens, próximo a $30 \mathrm{~kg} \mathrm{ha}^{-1} \mathrm{dia}^{-1}$, é considerável por ser apenas parte da produção do 
Tabela 2 - Porcentagem de matéria seca desaparecida da pastagem, dos componentes estruturais do capim elefante (CE) e dos componentes botânicos da entrelinha (EL) em três sistemas forrageiros. Santa Maria, RS, 2010.

\begin{tabular}{|c|c|c|c|c|c|c|c|c|c|c|c|c|}
\hline \multirow[t]{2}{*}{ Variáveis $^{2}$} & $\mathrm{SF}^{1}$ & Jul & Ago & Set & Out & Dez & Dez & Jan & Fev & Abr & Média & CV (\%) \\
\hline & $\mathrm{TE}$ & 29,13 & 29,14 & $48,15^{\mathrm{a}}$ & 46,67 & 47,38 & 31,09 & 37,24 & 23,40 & 33,90 & 36,23 & \\
\hline \multirow[t]{2}{*}{ MFT } & $\mathrm{AF}$ & 40,22 & 47,13 & $16,35^{\mathrm{b}}$ & 30,74 & 38,56 & 19,74 & 43,99 & 23,25 & 47,41 & 34,15 & 5,31 \\
\hline & TV & 56,14 & 50,82 & $57,74^{\mathrm{a}}$ & 36,57 & 34,38 & 24,52 & 27,25 & 19,21 & 35,45 & 38,01 & \\
\hline \multirow{3}{*}{ MFL } & $\mathrm{TE}$ & 31,15 & 0,00 & 61,58 & 68,35 & 73,46 & 59,60 & 67,98 & 58,02 & 67,80 & 43,13 & \\
\hline & $\mathrm{AF}$ & 35,41 & 0,00 & 11,43 & 53,11 & 53,19 & 34,99 & 68,08 & 31,68 & 68,37 & 39,58 & 17,74 \\
\hline & TV & 62,99 & 0,00 & 42,87 & 51,59 & 60,30 & 43,56 & 50,46 & 29,80 & 62,45 & 44,89 & \\
\hline \multirow{3}{*}{ MFEL } & $\mathrm{TE}$ & 26,33 & 62,34 & $45,02^{\mathrm{ab}}$ & 41,59 & 28,36 & 15,44 & 20,57 & 6,16 & 20,87 & 29,63 & \\
\hline & $\mathrm{AF}$ & 46,32 & 55,73 & $16,91^{\mathrm{b}}$ & 28,38 & 20,13 & 6,07 & 26,79 & 16,25 & 31,14 & 27,56 & 1,99 \\
\hline & TV & 48,58 & 64,26 & $57,82^{\mathrm{a}}$ & 33,95 & 19,03 & 7,72 & 15,53 & 5,65 & 16,48 & 29,89 & \\
\hline \multirow{3}{*}{ LFCE } & $\mathrm{TE}$ & $38,31^{b}$ & 0,00 & 41,83 & 70,19 & 76,77 & 62,92 & 80,84 & 80,80 & 86,65 & 59,81 & \\
\hline & $\mathrm{AF}$ & $28,10^{\mathrm{b}}$ & 0,00 & 23,82 & 66,92 & 62,60 & 47,40 & 81,45 & 71,28 & 86,95 & 52,05 & 3,02 \\
\hline & TV & $66,71^{\mathrm{a}}$ & 0,00 & 47,11 & 67,37 & 66,43 & 47,71 & 71,72 & 69,28 & 86,98 & 58,20 & \\
\hline \multirow{3}{*}{$\mathrm{AZ}$} & $\mathrm{TE}$ & 26,91 & 57,31 & 39,59 & $46,12^{\mathrm{a}}$ & - & - & - & - & - & 42,48 & \\
\hline & $\mathrm{AF}$ & 68,91 & 66,71 & 16,03 & $11,82^{\mathrm{C}}$ & - & - & - & - & - & 40,87 & 10,89 \\
\hline & TV & 48,56 & 68,80 & 53,20 & $26,61^{\mathrm{b}}$ & - & - & - & - & - & 49,29 & \\
\hline \multirow{3}{*}{ LEG } & $\mathrm{TE}$ & - & - & - & - & - & - & - & - & - & - & \\
\hline & $\mathrm{AF}$ & - & - & - & 39,25 & 26,73 & 4,62 & 32,24 & 11,52 & 41,06 & 26,90 & 20,35 \\
\hline & TV & 63,61 & 81,12 & 74,40 & 35,50 & 20,04 & 4,57 & 54,08 & - & - & 47,61 & \\
\hline \multirow{3}{*}{ ECE } & $\mathrm{TE}$ & 27,91 & 67,02 & 45,50 & 61,54 & 47,24 & 14,29 & 30,04 & 2,71 & 6,26 & 32,24 & \\
\hline & $\mathrm{AF}$ & 37,53 & 47,02 & 17,31 & 48,55 & 18,65 & 13,45 & 43,43 & 32,07 & 66,35 & 37,48 & 13,11 \\
\hline & TV & 62,60 & 82,47 & 46,20 & 33,31 & 16,25 & 12,57 & 35,80 & 13,14 & 34,59 & 37,43 & \\
\hline \multirow{3}{*}{ MSD } & $\mathrm{TE}$ & 2,39 & 4,36 & $3,86^{\mathrm{a}}$ & 3,62 & 3,17 & 2,23 & $2,54^{\mathrm{ab}}$ & 1,49 & 2,25 & 2,88 & \\
\hline & $\mathrm{AF}$ & 3,29 & 3,90 & $1,27^{\mathrm{b}}$ & 2,23 & 2,69 & 1,46 & $3,01^{\mathrm{a}}$ & 1,52 & 3,17 & 2,51 & 4,19 \\
\hline & $\mathrm{TV}$ & 4,83 & 4,49 & $4,48^{\mathrm{a}}$ & 2,73 & 2,26 & 1,85 & $1,81^{b}$ & 1,44 & 2,36 & 2,92 & \\
\hline
\end{tabular}

'a b’ médias seguidas por letras distintas, na coluna, diferem entre si pelo teste de Tukey $(\mathrm{P} \leq 0,05)$.

${ }^{1} \mathrm{TE}=$ testemunha, constituído por capim elefante $(\mathrm{CE})+$ azevém anual $(\mathrm{AZ})$ + espécies de crescimento espontâneo (ECE); AF= CE + AZ + $\mathrm{ECE}+$ amendoim forrageiro; $\mathrm{TV}=\mathrm{CE}+\mathrm{AZ}+\mathrm{ECE}+$ trevo vermelho.

${ }^{2} \mathrm{MFL}=$ massa de forragem da linha; $\mathrm{MFEL}=$ massa de forragem da entrelinha; $\mathrm{LFCE}=$ lâmina foliar do CE; LEG= leguminosa; $\mathrm{MMEL}=$ material morto da entrelinha; ECE= espécies de crescimento espontâneo; MSD= matéria seca desaparecida com base em $100 \mathrm{~kg}$ de peso vivo.

período hibernal. Resultado superior, com 37,8kg ha-1 dia $^{-1}$, foi obtido por SILVA et al. (2005) em aveia e azevém anual, utilizando $100 \mathrm{~kg} \mathrm{ha}^{-1}$ de nitrogênio.

Para as leguminosas, as taxas de acúmulo de forragem foram semelhantes, sendo, em média, de $11,09 \mathrm{~kg} \mathrm{ha}^{-1} \mathrm{dia}^{-1}$. Comparativamente, observa-se menor variabilidade nas taxas obtidas com amendoim forrageiro em relação ao trevo vermelho, implicando condição mais favorável para se manter oferta de forragem de qualidade no decorrer dos pastejos, considerando o elevado valor nutritivo dessa leguminosa (OLIVO et al., 2009). 
Tabela 3 - Taxa de acúmulo diário da pastagem (TAD), da linha (TAL), da entrelinha (TAE), de lâminas foliares do capim elefante (TACE), dos componentes botânicos constituídos por azevém anual (TAZ), leguminosas (TALEG), Paspalum (TAPAS) e das espécies de crescimento espontâneo (TAECE) em três sistemas forrageiros. Santa Maria, RS, 2010.

\begin{tabular}{|c|c|c|c|c|c|c|c|c|c|c|c|c|}
\hline \multirow[t]{2}{*}{ Variáveis } & \multirow[t]{2}{*}{$\mathrm{SF}^{1}$} & Ago & Set & $\begin{array}{c}\text { Out } \\
-2009\end{array}$ & Dez & Dez & -------- & $\begin{array}{c}\text { Fev } \\
-2010--\end{array}$ & --------- & \multirow[t]{2}{*}{ Média } & \multirow[t]{2}{*}{$\begin{array}{l}\text { Produção } \\
\left(\mathrm{t} \mathrm{ha}^{-1}\right)\end{array}$} & \multirow[t]{2}{*}{$\begin{array}{l}\text { CV } \\
(\%)\end{array}$} \\
\hline & & \multicolumn{8}{|c|}{ Acúmulo diário de MS (kg ha-1) } & & & \\
\hline \multirow{3}{*}{ TAD } & TE & 30,18 & 48,69 & 63,97 & 49,33 & 85,23 & 61,21 & 33,32 & 37,51 & 51,18 & 17,14 & \multirow{3}{*}{9,11} \\
\hline & $\mathrm{AF}$ & 34,18 & 50,07 & 37,85 & 46,31 & 66,46 & 62,96 & 56,10 & 47,36 & 50,16 & 16,80 & \\
\hline & TV & 46,17 & 97,22 & 52,11 & 36,31 & 78,26 & 55,03 & 61,56 & 38,37 & 58,13 & 19,47 & \\
\hline \multirow{3}{*}{ TAL } & TE & 0,01 & 4,76 & 8,04 & 25,02 & 34,67 & 34,07 & 22,99 & 17,12 & 18,33 & 6,14 & \multirow{3}{*}{14,50} \\
\hline & $\mathrm{AF}$ & 0,01 & 6,13 & 2,44 & 29,45 & 32,17 & 27,49 & 36,57 & 25,63 & 19,98 & 6,69 & \\
\hline & TV & 0,01 & 5,43 & 5,70 & 20,27 & 51,88 & 22,85 & 52,83 & 20,54 & 22,43 & 7,52 & \\
\hline \multirow{3}{*}{ TAE } & TE & 30,18 & 43,93 & 55,93 & 24,31 & 50,55 & 27,13 & 10,32 & 20,39 & 32,84 & 11,00 & \multirow{3}{*}{9,52} \\
\hline & $\mathrm{AF}$ & 34,18 & 43,94 & 35,40 & 16,86 & 34,29 & 35,47 & 19,52 & 21,72 & 30,17 & 10,11 & \\
\hline & TV & 46,17 & 91,79 & 46,41 & 16,04 & 26,37 & 32,18 & 8,72 & 17,83 & 35,69 & 11,96 & \\
\hline \multirow{3}{*}{ TACE } & $\mathrm{TE}$ & 0,01 & 2,62 & 5,65 & 19,65 & 20,71 & 27,21 & 21,55 & 15,36 & 14,09 & 4,72 & \multirow{3}{*}{14,17} \\
\hline & $\mathrm{AF}$ & 0,01 & 3,61 & 2,10 & 19,59 & 20,38 & 26,69 & 28,82 & 25,58 & 15,51 & 5,31 & \\
\hline & TV & 0,01 & 4,55 & 3,84 & 16,51 & 26,38 & 21,48 & 30,81 & 20,53 & 15,85 & 5,20 & \\
\hline \multirow{3}{*}{ TAZ } & $\mathrm{TE}$ & 22,58 & 32,50 & 34,68 & - & - & - & - & - & 29,92 & 10,02 & \multirow{3}{*}{28,07} \\
\hline & $\mathrm{AF}$ & 29,14 & 31,65 & 15,09 & - & - & - & - & - & 25,29 & 8,47 & \\
\hline & TV & 29,01 & 52,61 & 19,27 & - & - & - & - & - & 33,63 & 11,27 & \\
\hline \multirow{3}{*}{ TALEG } & $\mathrm{TE}$ & - & - & - & - & - & - & - & - & - & - & \multirow{3}{*}{12,22} \\
\hline & $\mathrm{AF}$ & - & - & $12,31^{\mathrm{b}}$ & 11,96 & 12,26 & $12,76^{\mathrm{a}}$ & 10,61 & 7,17 & 11,18 & 3,74 & \\
\hline & TV & 8,31 & 28,42 & $20,13^{\mathrm{a}}$ & 2,92 & 4,98 & $1,23^{\mathrm{b}}$ & - & - & 11,00 & 3,68 & \\
\hline \multirow{3}{*}{ TAPAS } & TE & - & - & - & 11,75 & 24,13 & 8,07 & $9,30^{\mathrm{a}}$ & 19,17 & $14,61^{\mathrm{a}}$ & $4,89^{\mathrm{a}}$ & \multirow{3}{*}{11,59} \\
\hline & $\mathrm{AF}$ & - & - & - & 4,08 & 6,79 & 10,99 & $0,01^{\mathrm{b}}$ & 9,62 & $6,29^{\mathrm{b}}$ & $2,11^{\mathrm{b}}$ & \\
\hline & TV & - & - & - & 8,00 & 5,34 & 13,65 & $0,01^{\mathrm{b}}$ & 13,46 & $8,09^{b}$ & $2,71^{\mathrm{b}}$ & \\
\hline \multirow{3}{*}{ TAECE } & $\mathrm{TE}$ & 7,60 & 11,42 & 21,24 & 12,56 & 26,41 & 18,44 & 1,02 & 1,22 & 12,49 & 4,18 & \multirow{3}{*}{12,32} \\
\hline & $\mathrm{AF}$ & 5,04 & 12,29 & 7,99 & 0,82 & 15,23 & 11,71 & 8,91 & 4,92 & 8,36 & 2,80 & \\
\hline & TV & 8,84 & 10,76 & 6,99 & 5,11 & 16,04 & 17,29 & 8,72 & 4,36 & 9,76 & 3,27 & \\
\hline
\end{tabular}

‘a b’ médias seguidas por letras distintas, na coluna, diferem entre si pelo teste de Tukey $(\mathrm{P} \leq 0,05)$.

${ }^{1} \mathrm{TE}=$ testemunha, constituído por capim elefante $(\mathrm{CE})+$ azevém anual $(\mathrm{AZ})+$ espécies de crescimento espontâneo $(\mathrm{ECE}) ; \mathrm{AF}=\mathrm{CE}+\mathrm{AZ}+$ $\mathrm{ECE}+$ amendoim forrageiro; TV= CE + AZ + ECE+ trevo vermelho.

Para as espécies de crescimento espontâneo, houve diferença $(\mathrm{P} \leq 0,05)$ para o Paspalum spp., maior componente dessa fração, com valores mais baixos no consórcio com as leguminosas, confirmando a ação delas no controle da vegetação espontânea (SARRANTONIO, 1992).
Quanto à produção de forragem, não houve diferenças entre os sistemas, verificando-se um valor médio de $18 \mathrm{tha}^{-1}$ de matéria seca. STEINWANDTER et al. (2009) encontraram valores médios superiores, com $23 \mathrm{tha}^{-1}$ de matéria seca, em pastagens consorciadas com distintas leguminosas, mas usando maior quantidade de adubação nitrogenada. 


\section{CONCLUSÃO}

Os sistemas forrageiros constituídos por espécies de ciclos distintos, implantados e manejados com tecnologias e insumos que proporcionam baixo impacto ambiental, demonstram complementaridade e baixa variabilidade na produção de forragem. A taxa de acúmulo de matéria seca do trevo vermelho foi superior, proporcionando uma diminuição do crescimento das espécies de crescimento espontâneo, com a inclusão de leguminosas no sistema forrageiro.

A inclusão de leguminosas aos sistemas implica efeitos sinérgicos, com redução de espécies de crescimento espontâneo e melhoria do desempenho animal, evidenciado no melhor desempenho do consórcio com trevo vermelho.

\section{REFERÊNCIAS}

CADISH, G. et al. Nitrogen cycling in a pure grass pasture and a grass-legume misture on a red latosol in Brazil. Tropical Grasslands, v.28, n.1, p.43-52, 1994.

CASTILHO, A.R. Potencial produtivo de ecotipos de Arachispintoi em el Piedemonte de los Llanos Orientales de Colombia. PasturasTropicales, v.23, n.1, p.19-24, 2001.

DERESZ, F. Influência do período de descanso da pastagem de capim elefante na produção de leite de vacas mestiças Holandês x Zebu. Revista Brasileira de Zootecnia [online], v.30, n.2, p.461-469, 2001. ISSN 1806-9290. Disponível em: <http:/ /www.scielo.br/pdf/rbz/v30n2/5489.pdf>. Acesso em: $14 \mathrm{fev}$. 2011. doi: 10.1590/S1516-35982001000200024.

MISSIO, R. et al. Massa de lâminas foliares nas características produtivas e qualitativas da pastagem de capim elefante Pennisetum purpureum, Schum (cv. 'Taiwan') e desempenho animal. Ciência Rural, [online], v.36, n.4, p.1243-1248, 2006. ISSN 0103-8478. Disponível em: <http://www.scielo.br/ pdf/cr/v36n4/a30v36n4.pdf>. Acesso em: 12 jan. 2011. doi: 10.1590/S0103-84782006000400030.

OLIVO, C.J. et al. Produção de forragem e carga animal em pastagens de capim elefante consorciadas com azevém, espécies de crescimento espontâneo e trevo-branco ou amendoim forrageiro. Revista Brasileira de Zootecnia, [online], v.38, n.1, p.27-33, 2009. ISSN 1806-9290. Disponível em: <http:/ /www.scielo.br/pdf/rbz/v38n1/a04v38n1.pdf>. Acesso em: 31 jan. 2011. doi: 10.1590/S1516-35982009000100004.

PAIM, N.R. Melhoramento genético de leguminosas forrageiras. In: PEIXOTO, A.M. et al. Pastagens: fundamentos da exploração racional. 2.ed. Piracicaba: FEALQ, 1994. p.893908. (Série atualização em zootecnia, 10).

PERIN, A.et al. Cobertura do solo e acumulação de nutrientes pelo amendoim forrageiro. Pesquisa Agropecuária Brasileira, [online], v.38, n.7, p.791-796, 2003. ISSN 0100204X. Disponível em: <http://www.scielo.br/pdf/pab/v38n7/ 18200.pdf $>$. Acesso em: 09jun 2009. doi: 10.1590/S0100204X2003000700002.

SARRANTONIO, M. Opportunities and challenges for the inclusion of soil-improving crops in vegetable production systems. HortScience, v.27, n.7, p.754-758, 1992.

SAS INSTITUTE, SAS. User's guide: statistics. Version 6.11. Cary, 1997. 842p.

SILVA, A.C.F. et al. Alternativa de manejo de pastagem hibernal: níveis de biomassa de lâmina foliar verde. Revista Brasileira de Zootecnia, [online], v.34, n.2, p.472-478, 2005. ISSN 1806-9290. Disponível em: <http://www.scielo.br/pdf/rbz/ v34n2/25458.pdf $>$. Acesso em: 09 jun. 2009. doi: 10.1590/ S1516-35982005000200014.

STEINWANDTER, E. et al. Produção de forragem em pastagens consorciadas com diferentes leguminosas sob pastejo rotacionado. Acta Scientiarum. Animal Sciences, [online], v.31, n.2, p.131-137, 2009. ISSN 1807-8672. Disponível em: <http://www.periodicos.uem.br/ojs/index.php/ActaSciAnimSci/ article/view/6238/6238>. Acesso em: 17 jan. 2011. doi: 10.4025/actascianimsci.v31i2.6238

THOMAS, R.J. The role of the legume in the nitrogen cycle of productive and sustainable pastures. Grass and Forage Science, v.47, n.1, p.133-142, 1992.

WILM, H.G. et al. Estimating forage yield by the double sampling method. Journal of American Society of Agronomy, v.36, n.1, p.194-203, 1944. 